\title{
ACTH Action on Messenger RNA Stability Mechanisms
}

\author{
Agnès Desroches-Castan ${ }^{1,2,3}$, Jean-Jacques Feige ${ }^{1,2,3}$ and Nadia Cherradi ${ }^{1,2,3 *}$ \\ ${ }^{1}$ Institut National de la Santé et de la Recherche Médicale, INSERM U1036, Grenoble, France, ${ }^{2}$ Commissariat à l'Energie \\ Atomique et aux Energies Alternatives, Institut de Biosciences et Biotechnologies de Grenoble, Laboratoire Biologie du \\ Cancer et de l'Infection, Grenoble, France, ${ }^{3}$ Université Grenoble Alpes, Unité Mixte de Recherche-S1036, Grenoble, France
}

\section{OPEN ACCESS}

Edited by:

Antoine Martinez,

Centre National de la Recherche Scientifique (CNRS), France

Reviewed by:

Enzo Lalli,

INSERM, France

Kazuhiro Takahashi,

Tohoku University, Japan

*Correspondence:

Nadia Cherradi

nadia.cherradi@cea.fr

Specialty section:

This article was submitted to

Neuroendocrine Science,

a section of the journal

Frontiers in Endocrinology

Received: 06 December 2016

Accepted: 05 January 2017

Published: 20 January 2017

Citation:

Desroches-Castan A, Feige J-J and Cherradi N (2017) ACTH Action on

Messenger RNA Stability

Mechanisms.

Front. Endocrinol. 8:3.

doi: 10.3389/fendo.2017.00003
The regulation of mRNA stability has emerged as a critical control step in dynamic gene expression. This process occurs in response to modifications of the cellular environment, including hormonal variations, and regulates the expression of subsets of proteins whose levels need to be rapidly adjusted. Modulation of messenger RNA stability is usually mediated by stabilizing or destabilizing RNA-binding proteins (RNA-BP) that bind to the $3^{\prime}$-untranslated region regulatory motifs, such as AU-rich elements (AREs). Destabilizing ARE-binding proteins enhance the decay of their target transcripts by recruiting the mRNA decay machineries. Failure of such mechanisms, in particular misexpression of RNA-BP, has been linked to several human diseases. In the adrenal cortex, the expression and activity of mRNA stability regulatory proteins are still understudied. However, ACTH- or CAMP-elicited changes in the expression/phosphorylation status of the major mRNA-destabilizing protein TIS11b/BRF1 or in the subcellular localization of the stabilizing protein Human antigen $\mathrm{R}$ have been reported. They suggest that this level of regulation of gene expression is also important in endocrinology.

Keywords: ACTH, AU-rich elements, RNA-binding proteins, TIS11b/BRF1, HuR, tristetraprolin, mRNA stability

\section{INTRODUCTION}

Transcriptional regulation of the cellular responses to hormones has been the primary focus of many endocrinological research studies during the past decades. Although the transcriptional mechanisms that regulate the production of specific mRNAs are undoubtedly important, it has become increasingly evident that processes regulating the stability of mRNAs also represent critical steps in the control of dynamic gene expression. In particular, acute changes in gene expression are now recognized to be controlled by RNA-binding proteins (RNA-BP) and microRNAs through their binding to target transcripts and their positive or negative regulation of mRNA turnover. Because the ability to respond to rapid changes in ACTH levels is essential for maintaining steroid hormone homeostasis, posttranscriptional mechanisms are expected to be involved in ACTH action. The pleiotropic effects exerted by ACTH on adrenocortical cell functions are regulated through a multiplicity of mechanisms. Through binding to its adenylate-cyclase-coupled receptor MC2R, ACTH stimulates the release of cAMP and the activation of the cAMP-dependent protein kinase A (PKA), which in turn phosphorylates and regulates a number of specific substrates including the steroidogenic acute regulatory protein (StAR) (1) and the cAMP response element-binding protein (CREB) (2). ACTH also strongly regulates the transcription of a number of genes involved in the

Abbreviations: TIS11b, TPA-inducible sequence 11b; BRF1, butyrate response factor 1; ZFP36, zinc finger protein; TTP, tristetraprolin; CCR4, carbon catabolite repressor protein 4; CNOT1, CCR4-NOT transcription complex subunit 1; Dcp1a, decapping enzyme la. 
steroidogenic response including those encoding several steroidogenic enzymes (3), components of the extracellular matrix (4) and many others. Another less characterized level of regulation through which ACTH exerts its actions is the control of mRNA stability through the activity of specific proteins that bind the $3^{\prime}$-untranslated region ( $3^{\prime}$-UTR) of target mRNAs. We were first to observe that the increase in vascular endothelial growth factorA (VEGF-A) mRNA induced by ACTH in primary adrenocortical fasciculata cells did not result from increased transcription (5) but from stabilization of its mRNA (6). Here, we will present the proteins that mediate the regulation of short-lived mRNA stability/degradation and focus on those which are regulated by ACTH in adrenocortical cells.

\section{mRNA STABILITY MECHANISMS: AN INTERPLAY BETWEEN CIS-ACTING ELEMENTS AND TRANS-ACTING FACTORS}

The steady-state level of any mRNA in an eukaryotic cell results from the balance between its synthesis through gene transcription and its degradation through the mRNA decay machinery. Regulation of mRNA stability implies both cis elements mainly located in the $3^{\prime}$-UTR of mRNAs and trans-acting factors. These latter factors comprise a number of RNA-BP that specifically bind distinct cis elements, form multimolecular scaffolds that favor or prevent the subsequent recruitment of the mRNA deadenylation and mRNA degradation machineries (Figure 1A) (7). Eukaryotic mRNAs are protected at both extremities by a 7-methyl guanosine cap at their $5^{\prime}$-end that confers resistance to $5^{\prime}$ to $3^{\prime}$ exonucleases and by a poly(A)-tail recruiting the poly(A)-binding protein $(\mathrm{PABP})$ at their $3^{\prime}$-end that confers resistance to $3^{\prime}$ to $5^{\prime}$ exonuclease attack by the exosome complex (8). The most frequently distributed and best-studied cis elements are the AU-rich elements (AREs) that are often arranged in mRNA 3'-UTRs as repeated AUUUA pentameric sequences that eventually overlap (9). More than 6,000 human ARE-containing mRNAs have been listed in the last upgrade of the ARED 3.0 database (http://brp. kfshrc.edu.sa/ARED/) (10). Many of them have a short half-life, rendering this regulatory process highly effective to rapidly turn down a cellular function.

\section{AREs BINDING PROTEINS}

Among the more than 20 ARE-binding proteins (ARE-BP) identified so far, some are destabilizing the target mRNA by recruiting deadenylases and exonucleases and some are stabilizing them by protecting them from these degradation enzymes. The competition between both types of proteins for a given ARE will ultimately determine the fate of the target mRNA. The best characterized stabilizing ARE-BP is human antigen R (HuR), which is a member of the ELAV (homologs of the Drosophila proteins embryonic lethal abnormal vision) family (11). HuR is ubiquitously expressed and is predominantly localized in the nucleus of non-stimulated cells where it forms messenger ribonucleoprotein complexes that are assembled during splicing of primary transcripts, prior to transport of mature mRNAs to the cytoplasm (12). Upon cell activation by various stimuli, HuR undergoes CRM1-dependent nuclear-cytoplasmic shuttling, directed by localization signals (13). Binding of HuR to ARE may play important roles in controlling the processing, splicing, and polyadenylation of the nuclear transcript, together with the nuclear export and stabilization/ translation in the cytoplasm. The exact mechanism by which HuR stabilizes target mRNAs is still unclear, but HuR has been reported in many cell types to prevent the degradation of target mRNAs by competing with destabilizing proteins and thereby preventing their recruitment of the exosome machinery $(6,14)$. A larger number of destabilizing proteins has been described. Among them, the tristetraprolin (TTP) family, which comprises three distinct members in mammals (TTP/TIS11/ZFP36, TIS11b/BRF1/ZFP36-L1, and TIS11d/BRF2/ZFP36-L2) is one of the best characterized. Although they all bind to similar synthetic sequences in vitro, members of the TTP family present specific sites of action and preferential targets in vivo, as demonstrated by the distinct phenotypes of the mice that have been genetically invalidated for each of these genes. In TTP-KO mice, the TNF $\alpha$ mRNA is significantly stabilized in macrophages, resulting in a fatal postnatal inflammatory syndrome (15). Deletion of TIS11b/ BRF1 gene in mice results in embryonic lethality due to abnormal placentation and major vascular defects $(16,17)$. This is mainly caused by the failure of TIS11b to repress the expression of VEGF at the end of the developmental angiogenic process. The complete invalidation of the TIS11d gene causes postnatal lethality due to defective definitive hematopoiesis (18). Structural studies have shown that the tandem zing finger repeats of TTP family proteins bind to the $5^{\prime}$-UUAUUUA(U/A)(U/A)-3' recognition motif while the $\mathrm{C}$-terminal and $\mathrm{N}$-terminal domains of the proteins participate in the recruitment of the mRNA deadenylation and mRNA degradation enzymes $(19,20)$. Other destabilizing ARE-BP include $\mathrm{KH}$-splicing regulatory protein (KSRP) and the AU-rich RNA-binding factor 1 (AUF1/HnRNP D).

\section{ACTH ACTION ON MRNA DECAY MECHANISMS: FROM TRANSCRIPTION TO PHOSPHORYLATION OF ARE-BP}

TIS11b, also named BRF1 or ZFP36-L1, was identified in the adrenal cortex through a differential display RT-PCR analysis of ACTH-stimulated versus non-stimulated adrenocortical cells (21). HuR and alternatively spliced isoforms of AUF1/hnRNPD are also expressed in adrenal cells $(6,22)$. Recently, it was established that ACTH induced $z f p 36-L 1$ gene transcription in bovine adrenocortical cells (BAC) through phosphorylation of CREB transcription factor and CREB-mediated activation of TIS11b promoter (23). A highly conserved cAMP response element (CRE) was found at -402 to -394 relative to the transcription start site (TSS) of human $z f p 36-L 1$ gene. TIS11b mRNA is also rapidly stimulated by 8 -bromo-cAMP in murine adrenocortical Y-1 cells or Leydig MA-10 cells (22), suggesting that the protein is a key regulator of endocrine tissue biology. Interestingly, no classical CRE was identified within the $-2,000$ bp upstream of the TSS of the two other family members TTP and TIS11d. In agreement 


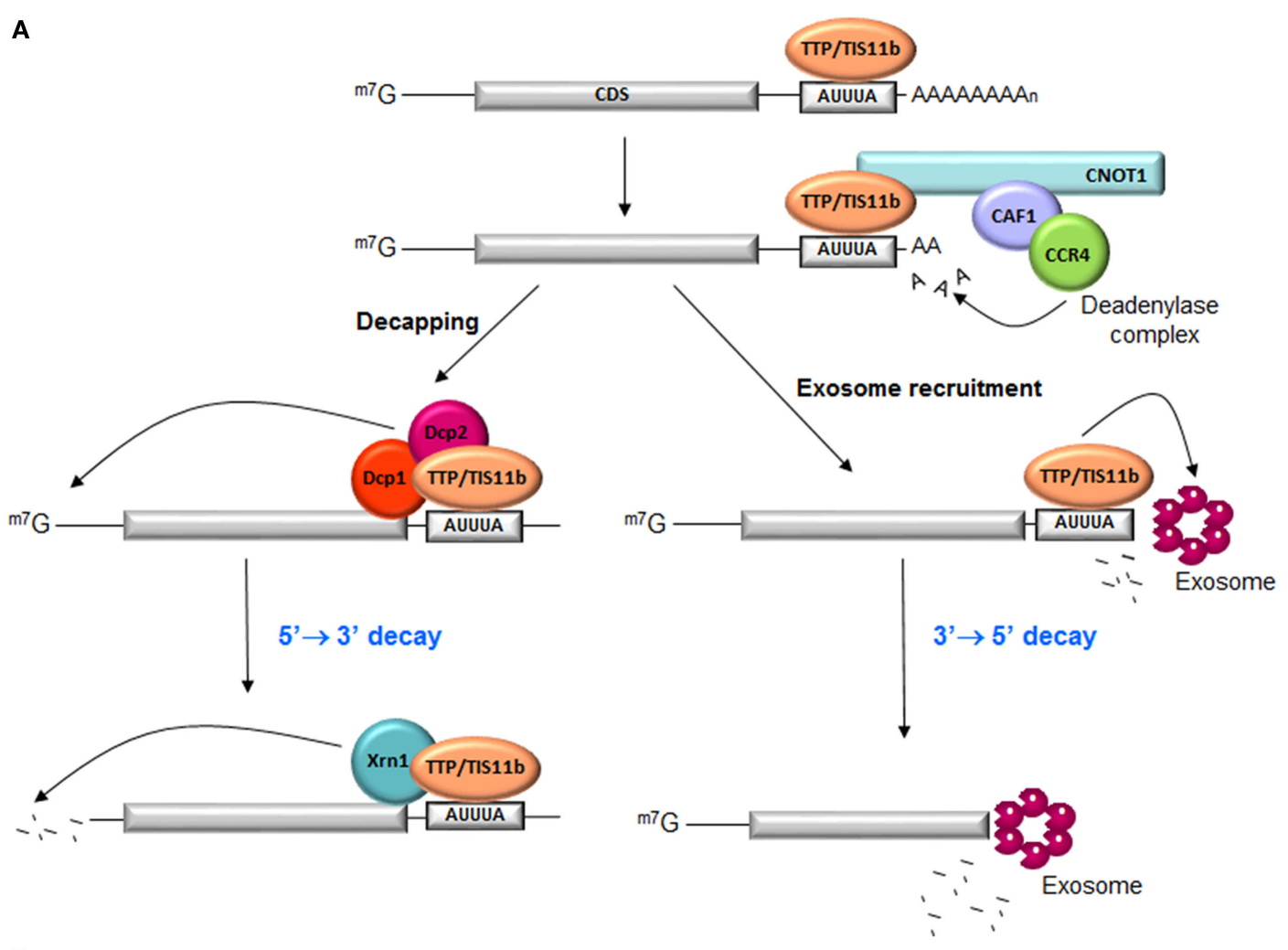

B

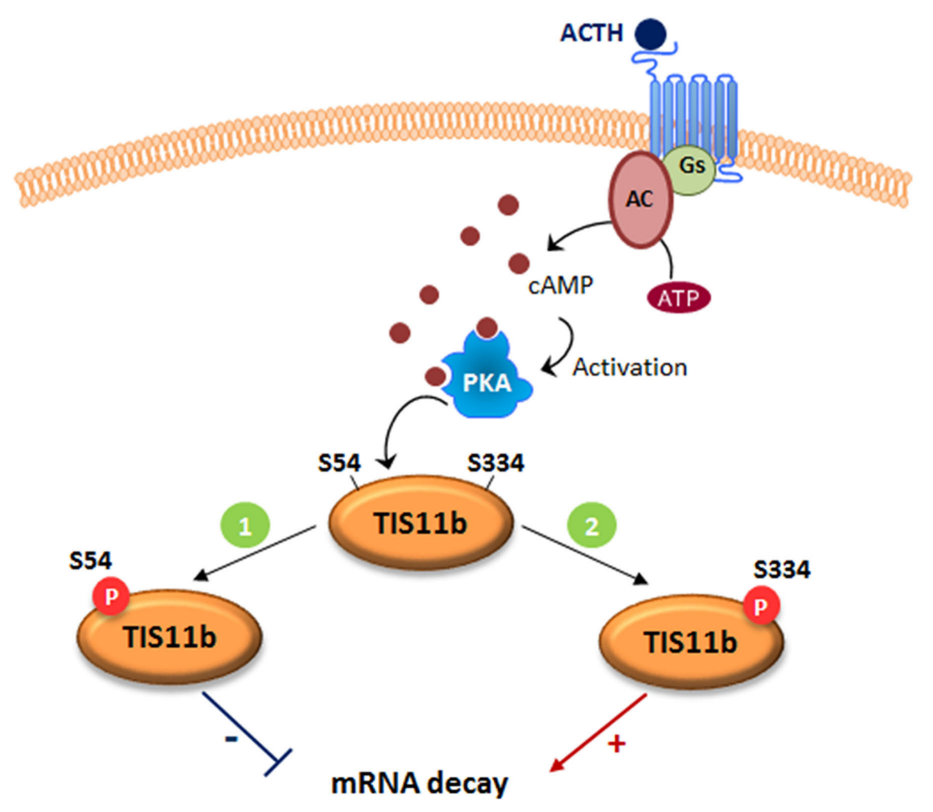

FIGURE 1 | Function of tristetraprolin (TTP) and TIS11b in ARE-mediated mRNA decay. (A) TTP and TIS11b bind to AU-rich elements in the 3'-UTR of target mRNAs and recruit the deadenylase complex directly (CCR4-CAF-NOT1 complex) to trigger mRNA deadenylation. Deadenylated transcripts are degraded through TTP- or TIS11b-mediated recruitment of the exosome, a multiprotein complex that promotes the $3^{\prime}$ to $5^{\prime}$ mRNA decay. Alternatively, deadenylation can be followed by mRNA decapping by the decapping enzymes Dcp1/Dcp2 and the $5^{\prime}$ to $3^{\prime}$ mRNA degradation by the Xrn1 exonuclease. CDS, coding sequence. (B) Two putative protein kinase A (PKA) phosphorylation sites, S54 and S334, were identified in TIS11b protein sequence with important roles in protein activity and stability. ACTH stimulation increases intracellular CAMP levels through the action of the G protein Gs and the adenylyl cyclase. This leads to activation of PKA (1). Phosphorylation of TIS11b at S54 by PKA inhibits protein activity. TIS11b-phospho-S54 is sequestered in the cytoplasm due to enhanced interaction with 14-3-3 proteins. This mechanism would promote vascular endothelial growth factor (VEGF) mRNA induction (2). To turn down VEGF production, phosphorylation of TIS11b at S334 by PKA increases protein stability and activity. Dephosphorylation of both serines presumably by the phosphatase PP2A leads to degradation of TIS11b via the proteasome. 
with this observation, TTP or TIS11d mRNA levels were not changed upon ACTH challenge, pointing at a specific induction of TIS11b by the hormone in the adrenal cortex (23).

Two major target transcripts of TIS11b have been identified in the adrenal cortex. The first one is the message encoding the angiogenic cytokine VEGF (24). Knowing that VEGF mRNA was rapidly but transiently induced by ACTH in fasciculata cells through a transcription-independent mechanism, the contribution of TIS11b and HuR to this transient induction was investigated. Using HuR- and TIS11b-specific siRNAs, it was established that (i) ACTH induced nucleo-cytoplasmic translocation of $\mathrm{HuR}$ to trigger VEGF mRNA stabilization in the cytoplasm and (ii) TIS11b, which is induced later by ACTH, participates in the downregulation of VEGF mRNA levels. A short 75-bp long sequence in VEGF mRNA 3'-UTR was shown to bind TIS11b through two adjacent UUAUUUAAU and AUUUA motifs. The second identified target of TIS11b in endocrine cells is the StAR mRNA whose PKA-stimulated transcription paralleled TIS11b induction (22). StAR mediates intramitochondrial cholesterol transport in most steroidogenic tissues in response to hormonal changes (1). Cyclic AMP stimulates two major StAR transcripts of 3.5 and $1.6 \mathrm{~kb}$, which arise from differential use of polyadenylation signals and therefore differ only in their $3^{\prime}$-UTR (lengths 0.7 and $2.8 \mathrm{~kb}$, respectively). In mouse MA-10 and Y-1 cells, 8-bromo-cAMP stimulates StAR 3.5-kb mRNA as the predominant form. In BAC, similar long and short forms appear equally (21), whereas in human adrenocortical carcinoma cells H295R, di-butyryl-cAMP selectively stimulates the short form of StAR mRNA (25). Following translation, the $3.5-\mathrm{kb}$ StAR message is preferentially degraded after removal of the stimulus through the action of TIS11b binding to UAUUUAUU repeats in the extended $3^{\prime}$-UTR. This attenuation process provides a rapid mechanism to inactivate StAR when hormonal stimulation ceases.

ARE-binding proteins are also distal targets of several signaling pathways. TTP and TIS11b are phosphorylated by a variety of protein kinases. However, the impact of these phosphorylations on their mRNA-destabilizing activity is still a matter of debate, with some studies indicating that phosphorylations of TTP decrease its affinity for ARE-rich mRNAs (26) and other studies reporting that phosphorylations by ERK, p38 MAP-Kinase/MK2, or JNK kinase do not impact this affinity (27). Similarly, phosphorylation of TIS11b by PKB/Akt or MK2 at conserved serine residues did not affect its ability to bind AREs but nevertheless inhibited its ability to promote ARE-mRNA degradation $(28,29)$. The current accepted model suggests that protein-kinase activation leads to phosphorylation of TTP or TIS11b, favors their sequestration by 14.3.3 proteins, and thereby reduces their mRNA-destabilizing action. Upon signal extinction, dephosphorylation of TTP and TIS11b occurs probably via protein phosphatase PP2A and allows the recruitment of the mRNA decay ribonucleases. A new ACTH-regulated phosphorylation site recently identified in TIS11b seems, however, to mediate a different biological response. ACTH-mediated activation of PKA was reported to induce the phosphorylation of TIS11b on two serine residues, S54 and S334 (23) (Figure 1B). Analysis of phospho-dead (S54A, S334A) and phospho-mimick (S54D, S334D) TIS11b mutants revealed that $\mathrm{S} 54$ regulates the binding of TIS11b to 14.3 .3 protein but that S334 does not play a significant role in this interaction. In contrast, the C-terminal S334 phospho-site appears to be involved in the interaction with the CCR4-NOT1 deadenylation complex. TIS11b S334D phospho-mimick mutants presented a reduced association with CNOT1, a core subunit of the CCR4NOT deadenylase complex, but however displayed an enhanced interaction with the decapping enzyme Dcpla. Unexpectedly, this interaction was associated with an increased mRNA-destabilizing activity of TIS11b S334D as compared to the dephospho-form of TIS11b (23). These observations suggest that combinatorial phosphorylations of TIS11b on specific residues do not systematically abrogate their mRNA-destabilizing capability but rather fine-tune their interactions with the mRNA decay machineries.

\section{EXPRESSION OF TTP FAMILY MEMBERS IN ADRENOCORTICAL TUMORS}

Overexpression of ARE-containing transcripts encoding factors promoting growth, inflammation, angiogenesis, and invasion has been observed in carcinogenesis (30). These aberrant expressions results from dysfunctional ARE-mediated posttranscriptional control, which seems to be mainly due to deregulations in AREbinding proteins rather than to ARE mutations. Downregulation of TTP expression has been found in a variety of human malignancies including breast, colon, prostate, and lung cancers (31-33). The loss of TTP expression seems to be an early event during tumorigenesis. Nevertheless, apart from single-nucleotide polymorphisms associated with decreased translation efficiency, the mechanisms leading to TTP suppression in cancer remain obscure. Analysis of the mRNA expression levels of TTP family members (TTP, TIS11b, and TIS11d) and HuR in human adrenocortical tumors revealed that TTP mRNA was dramatically decreased in adrenocortical adenoma (ACA) and adrenocortical carcinomas (ACC) as compared to normal adrenal cortex (NAC) (Figure 2). By contrast, TIS11b mRNA is highly expressed in ACC as compared to ACA and NAC while the expression of the third member of the family TIS11d was similar in all the tissues examined. No significant difference in HuR expression was found between normal cortex and adrenocortical tumors. Remarkably, the expression patterns of TTP and TIS11b are symmetrically opposite in normal adrenal cortex and malignant tumors. The relevance of these variations to human physiology and the pathology of adrenocortical cancer remains to be determined. In addition, these results will require validation by measurement of TTP and TIS11b protein levels.

\section{CLOSING REMARKS AND PERSPECTIVES}

Transcriptional regulation has been considered the primary control point of protein production in eukaryotic cells. However, there is growing evidence of pivotal posttranscriptional regulation for many genes, including those involved in differentiated functions of the adrenal cortex such as the StAR gene. This has prompted extensive investigations to elucidate the mechanisms controlling RNA processing, mRNA nuclear export and localization, mRNA stability, and turnover, in addition to translational 

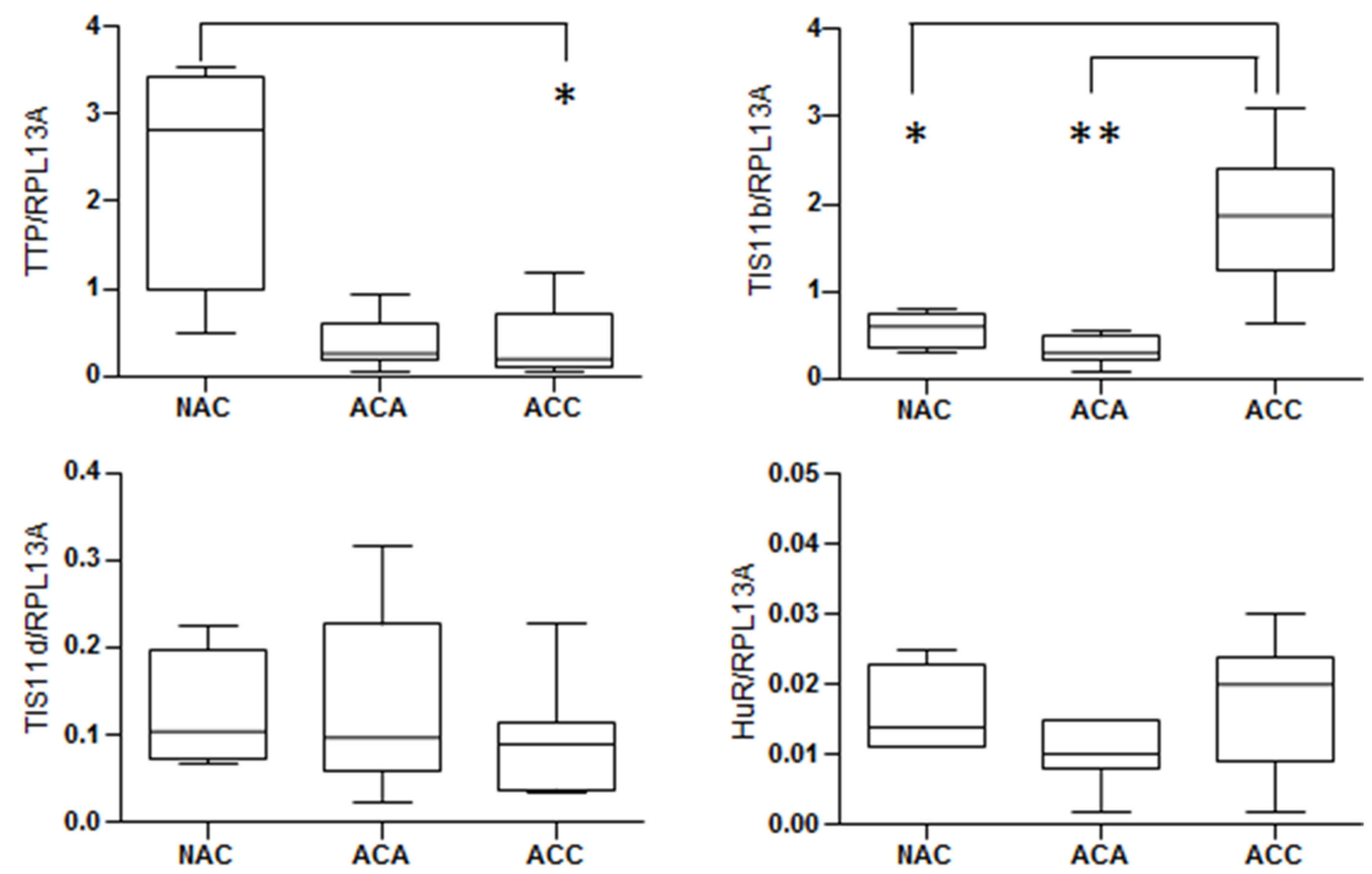

FIGURE 2 | Expression of mRNA stability regulators in human adrenocortical tumors. Relative expression of mRNA stability factors in adrenocortical tumor samples from the French COMETE (COrtico et MEdullosurrénales, Tumeurs Endocrines) Network. TTP family members (TTP, TIS11b, and TIS11d) and HuR were quantified by reverse transcription-quantitative PCR in 4 normal adrenal cortex, 11 cortisol-producing adrenocortical adenomas, and 15 adrenocortical carcinomas. RPL13A was used as housekeeping gene for normalization. The graphs show median with interquartile range. All data were analyzed using the GraphPad Prism Software and were considered as statistically different when $p<0.05\left(^{*}\right)$ and $p<0.01{ }^{\left({ }^{*}\right)}$.

rates and posttranslational events. The regulation of mRNA stability has emerged as a critical control step in determining the cellular mRNA level, which is regulated through specific RNA sequence elements-protein interactions. In this context, study of the hormonal control of mRNA stability regulatory proteins and their activity in adrenal cortex function is just beginning. Considering that acute ACTH treatment affects a large number of transcripts, it seems very likely that mRNA stability regulations might play an important role in these transient gene expressions. These mechanisms are expected to also operate in response to other cAMP-mobilizing hormones in their respective target organs. For example, parathyroid hormone has been shown to decrease sodium/hydrogen exchanger 3 mRNA stability through the action of the destabilizing protein KSRP in kidney epithelial cells (34). Importantly, few mRNA stability regulatory factors have been identified so far that appear to control a large pool of target mRNAs. This suggests that a slight alteration in the control mechanism may generate large-scale effects that could contribute to the development of complex disorders, including adrenal diseases. Efforts in studying mRNA stability regulators in adrenal cortex and their hormonal regulations should be made in order to better understand their potential contribution to adrenocortical pathologies and possibly discover potential biomarkers and therapeutic targets.

\section{AUTHOR CONTRIBUTIONS}

All authors listed have contributed to the work.

\section{FUNDING}

This work was funded through institutional support from INSERM, University Grenoble-Alpes and Commissariat à l'Energie Atomique et aux Energies Alternatives, and through grant support from the Fondation pour la Recherche Médicale and the Fondation ARC pour la Recherche sur le Cancer.

\section{REFERENCES}

1. Stocco DM. StAR protein and the regulation of steroid hormone biosynthesis. Annu Rev Physiol (2001) 63:193-213. doi:10.1146/annurev.physiol. 63.1.193

2. Lefrancois-Martinez AM, Blondet-Trichard A, Binart N, Val P, Chambon C, Sahut-Barnola I, et al. Transcriptional control of adrenal steroidogenesis:

novel connection between Janus kinase (JAK) 2 protein and protein kinase A (PKA) through stabilization of cAMP response element-binding protein (CREB) transcription factor. J Biol Chem (2011) 286:32976-85. doi:10.1074/ jbc.M111.218016

3. Sewer $M B$, Waterman MR. Insights into the transcriptional regulation of steroidogenic enzymes and StAR. Rev Endocr Metab Disord (2001) 2:269-74. doi:10.1023/A:1011516532335 
4. Feige JJ, Keramidas M, Chambaz EM. Hormonally regulated components of the adrenocortical cell environment and the control of adrenal cortex homeostasis. Horm Metab Res (1998) 30:421-5. doi:10.1055/s-2007978908

5. Gaillard I, Keramidas M, Liakos P, Vilgrain I, Feige JJ, Vittet D. ACTHregulated expression of vascular endothelial growth factor in the adult bovine adrenal cortex: a possible role in the maintenance of the microvasculature. JCell Physiol (2000) 185:226-34. doi:10.1002/1097-4652 (200011)185:2<226::AID-JCP7>3.0.CO;2-E

6. Cherradi N, Lejczak C, Desroches-Castan A, Feige JJ. Antagonistic functions of tetradecanoyl phorbol acetate-inducible-sequence $11 \mathrm{~b}$ and $\mathrm{HuR}$ in the hormonal regulation of vascular endothelial growth factor messenger ribonucleic acid stability by adrenocorticotropin. Mol Endocrinol (2006) 20:916-30. doi:10.1210/me.2005-0121

7. Stoecklin G, Muhlemann O. RNA decay mechanisms: specificity through diversity. Biochim Biophys Acta (2013) 1829:487-90. doi:10.1016/j.bbagrm. 2013.04.002

8. Planel S, Rataj F, Feige JJ, Cherradi N. Posttranscriptional regulation of angiogenesis through AU-rich mRNA degradation: potential application in cancer therapy. In: Feige JJ, Pagès G, Soncin F, editors. Molecular Mechanisms of Angiogenesis from Ontogenesis to Oncogenesis. France: Springer-Verlag (2014). p. 353-72.

9. Hitti E, Khabar KS. Sequence variations affecting AU-rich element function and disease. Front Biosci (Landmark Ed) (2012) 17:1846-60. doi:10.2741/4023

10. Bakheet T, Williams BR, Khabar KS. ARED 3.0: the large and diverse AUrich transcriptome. Nucleic Acids Res (2006) 34:D111-4. doi:10.1093/nar/ gkj052

11. Simone LE, Keene JD. Mechanisms coordinating ELAV/Hu mRNA regulons. Curr Opin Genet Dev (2013) 23:35-43. doi:10.1016/j.gde.2012. 12.006

12. Matsumoto K, Wassarman KM, Wolffe AP. Nuclear history of a pre-mRNA determines the translational activity of cytoplasmic mRNA. EMBO J (1998) 17:2107-21. doi:10.1093/emboj/17.7.2107

13. Fan XC, Steitz JA. HNS, a nuclear-cytoplasmic shuttling sequence in HuR. Proc Natl Acad Sci U S A (1998) 95:15293-8. doi:10.1073/pnas.95.26.15293

14. Linker K, Pautz A, Fechir M, Hubrich T, Greeve J, Kleinert H. Involvement of KSRP in the post-transcriptional regulation of human iNOS expression-complex interplay of KSRP with TTP and HuR. Nucleic Acids Res (2005) 33:4813-27. doi:10.1093/nar/gki797

15. Taylor GA, Carballo E, Lee DM, Lai WS, Thompson MJ, Patel DD, et al. A pathogenetic role for TNF alpha in the syndrome of cachexia, arthritis, and autoimmunity resulting from tristetraprolin (TTP) deficiency. Immunity (1996) 4:445-54. doi:10.1016/S1074-7613(00)80411-2

16. Stumpo DJ, Byrd NA, Phillips RS, Ghosh S, Maronpot RR, Castranio T, et al. Chorioallantoic fusion defects and embryonic lethality resulting from disruption of Zfp36L1, a gene encoding a CCCH tandem zinc finger protein of the Tristetraprolin family. Mol Cell Biol (2004) 24:6445-55. doi:10.1128/ MCB.24.14.6445-6455.2004

17. Bell SE, Sanchez MJ, Spasic-Boskovic O, Santalucia T, Gambardella L, Burton GJ, et al. The RNA binding protein Zfp3611 is required for normal vascularisation and post-transcriptionally regulates VEGF expression. Dev Dyn (2006) 235:3144-55. doi:10.1002/dvdy.20949

18. Stumpo DJ, Broxmeyer HE, Ward T, Cooper S, Hangoc G, Chung YJ, et al. Targeted disruption of Zfp3612, encoding a CCCH tandem zinc finger RNAbinding protein, results in defective hematopoiesis. Blood (2009) 114:2401-10. doi:10.1182/blood-2009-04-214619

19. Hudson BP, Martinez-Yamout MA, Dyson HJ, Wright PE. Recognition of the mRNA AU-rich element by the zinc finger domain of TIS11d. Nat Struct Mol Biol (2004) 11:257-64. doi:10.1038/nsmb738

20. Lykke-Andersen J, Wagner E. Recruitment and activation of mRNA decay enzymes by two ARE-mediated decay activation domains in the proteins TTP and BRF-1. Genes Dev (2005) 19:351-61. doi:10.1101/gad.1282305

21. Chinn AM, Ciais D, Bailly S, Chambaz E, LaMarre J, Feige JJ. Identification of two novel ACTH-responsive genes encoding manganese-dependent superoxide dismutase (SOD2) and the zinc finger protein TIS11b [tetradecanoyl phorbol acetate (TPA)-inducible sequence 11b]. Mol Endocrinol (2002) 16:1417-27. doi:10.1210/mend.16.6.0844

22. Duan H, Cherradi N, Feige JJ, Jefcoate C. cAMP-dependent posttranscriptional regulation of steroidogenic acute regulatory (STAR) protein by the zinc finger protein ZFP36L1/TIS11b. Mol Endocrinol (2009) 23:497-509. doi:10.1210/me.2008-0296

23. Rataj F, Planel S, Desroches-Castan A, Le Douce J, Lamribet K, Denis J, et al. The cAMP pathway regulates mRNA decay through phosphorylation of the RNA-binding protein TIS11b/BRF1. Mol Biol Cell (2016) 27:3841-54. doi:10.1091/mbc.E16-06-0379

24. Ciais D, Cherradi N, Bailly S, Grenier E, Berra E, Pouyssegur J, et al. Destabilization of vascular endothelial growth factor mRNA by the zinc-finger protein TIS11b. Oncogene (2004) 23:8673-80. doi:10.1038/sj.onc. 1207939

25. Clark BJ, Combs R. Angiotensin II and cyclic adenosine $3^{\prime}, 5^{\prime}$-monophosphate induce human steroidogenic acute regulatory protein transcription through a common steroidogenic factor-1 element. Endocrinology (1999) 140:4390-8. doi:10.1210/en.140.10.4390

26. Hitti E, Iakovleva T, Brook M, Deppenmeier S, Gruber AD, Radzioch D, et al. Mitogen-activated protein kinase-activated protein kinase 2 regulates tumor necrosis factor mRNA stability and translation mainly by altering tristetraprolin expression, stability, and binding to adenine/uridine-rich element. Mol Cell Biol (2006) 26:2399-407. doi:10.1128/MCB.26.6.23992407.2006

27. Chrestensen CA, Schroeder MJ, Shabanowitz J, Hunt DF, Pelo JW, Worthington MT, et al. MAPKAP kinase 2 phosphorylates tristetraprolin on in vivo sites including Ser178, a site required for 14-3-3 binding. J Biol Chem (2004) 279:10176-84. doi:10.1074/jbc.M310486200

28. Maitra S, Chou CF, Luber CA, Lee KY, Mann M, Chen CY. The AU-rich element mRNA decay-promoting activity of BRF1 is regulated by mitogen-activated protein kinase-activated protein kinase 2. RNA (2008) 14:950-9. doi:10.1261/ rna.983708

29. Schmidlin M, Lu M, Leuenberger SA, Stoecklin G, Mallaun M, Gross B, et al. The ARE-dependent mRNA-destabilizing activity of BRF1 is regulated by protein kinase B. EMBO J (2004) 23:4760-9. doi:10.1038/sj.emboj.7600477

30. Benjamin D, Moroni C. mRNA stability and cancer: an emerging link? Expert Opin Biol Ther (2007) 7:1515-29. doi:10.1517/14712598.7.10.1515

31. Brennan SE, Kuwano Y, Alkharouf N, Blackshear PJ, Gorospe M, Wilson GM. The mRNA-destabilizing protein tristetraprolin is suppressed in many cancers, altering tumorigenic phenotypes and patient prognosis. Cancer Res (2009) 69:5168-76. doi:10.1158/0008-5472.CAN-08-4238

32. Griseri P, Bourcier C, Hieblot C, Essafi-Benkhadir K, Chamorey E, Touriol C, et al. A synonymous polymorphism of the Tristetraprolin (TTP) gene, an AU-rich mRNA-binding protein, affects translation efficiency and response to Herceptin treatment in breast cancer patients. Hum Mol Genet (2011) 20:4556-68. doi:10.1093/hmg/ddr390

33. Al-Souhibani N, Al-Ahmadi W, Hesketh JE, Blackshear PJ, Khabar KS. The RNA-binding zinc-finger protein tristetraprolin regulates AU-rich mRNAs involved in breast cancer-related processes. Oncogene (2010) 29:4205-15. doi:10.1038/onc. 2010.168

34. Murray RD, Merchant ML, Hardin E, Clark B, Khundmiri SJ, Lederer ED. Identification of an RNA-binding protein that is phosphorylated by PTH and potentially mediates PTH-induced destabilization of Npt2a mRNA. Am J Physiol Cell Physiol (2016) 310:C205-15. doi:10.1152/ajpcell.00192.2015

Conflict of Interest Statement: The authors declare that the research was conducted in the absence of any commercial or financial relationships that could be construed as a potential conflict of interest.

Copyright (c) 2017 Desroches-Castan, Feige and Cherradi. This is an open-access article distributed under the terms of the Creative Commons Attribution License (CC $B Y)$. The use, distribution or reproduction in other forums is permitted, provided the original author(s) or licensor are credited and that the original publication in this journal is cited, in accordance with accepted academic practice. No use, distribution or reproduction is permitted which does not comply with these terms. 